\title{
Right Coronary Cusp of the Aortic Valve
}

National Cancer Institute

\section{Source}

National Cancer Institute. Right Coronary Cusp of the Aortic Valve. NCI Thesaurus. Code C127640.

The cusp of the aortic valve that overlies the right coronary ostium. 